\title{
Remote control by males of ovulation in bank voles (Clethrionomys glareolus)
}

\author{
J. R. Clarke and S. Hellwing* \\ Department of Agricultural Science, University of Oxford, Oxford, OXI 3PF, U.K. and \\ * Department of Zoology, University of Tel-Aviv, Israel
}

Investigation of bank voles (Clethrionomys glareolus) from the field led Brambell \& Rowlands (1936) to conclude that in this species ovulation occurs spontaneously during an oestrous cycle similar to that of the mouse. However, under laboratory conditions it has been shown that in several microtine rodents (e.g. Microtus spp. and Clethrionomys glareolus) ovulation is induced by copulation (Breed, 1967; Richmond \& Conaway, 1969; Clarke, Clulow \& Greig, 1970; Clulow \& Mallory, 1970; Cross, 1972; Gray, Davis, Zerylnick \& Dewsbury, 1974). The aim of the present work was to investigate whether ovulation in the bank vole can be induced by stimuli from males other than those provided by coitus.

\section{Methods}

Four experiments (A, B, C, D) were carried out, using sexually mature virgin females and males derived from the colony maintained in the Department of Agricultural Science, Oxford. The bank voles were kept in a lighting schedule of $16 \mathrm{~h}$ artificial light/day in a room in which there were no other animals. Whole oats, Oxoid rat and mouse breeding diet, hay, carrots and water were always available and cotton wool and sawdust were provided as bedding. Experiments A, B and C were designed to determine whether stimuli which could pass from males through a wire mesh could cause ovulation. Females were housed in plastic cages measuring $42 \times 25 \times 12 \mathrm{~cm}$ within each of which was a maze made of 6-mm square wire mesh. Bedding was only renewed when it became sodden through water bottle leakage. In Exp. $A$ there were two treatments: the maze in one cage was empty; the maze of the other was occupied by a male who was exchanged daily for another. Seven pairs of comparable females were assigned at random to treatments. Two or three females were simultaneously present in each cage. Experiment $B$ investigated the importance of the novelty of the male. There were 3 treatments lasting 7-15 days; (i) there was no male in the maze; (ii) the same male was present in the maze for the whole treatment period; (iii) the male in the maze was changed every 2 nd day. Experiment $C$ tested whether the number of males had any effect on the proportion of females ovulating. There were three treatments lasting 3-8 days: (i) there was no male in the maze; (ii) one or (iii) three males were in the mazes for the whole treatment period. In Exp. B six and in Exp. C five different trios of comparable females were randomly assigned to treatments and the various pairs (Exp. A) or trios (Exps B and C) were exposed to different males. Experiment $D$ was to examine whether ovulation might be induced by pheromonal stimuli. Trios of comparable females were randomly assigned to 3 treatments in which plastic cages measuring $30 \times 15 \times 13 \mathrm{~cm}$ were used; (i) females were moved back and forth every $48 \mathrm{~h}$ between a pair of cages containing bedding not soiled by males; (ii) and (iii) females were moved back and forth through pairs of cages soiled by 1 (ii) or 3 (iii) males: males had lived in one cage for $48 \mathrm{~h}$ before the start of treatments, and they were then moved into the other cage of the pair for $48 \mathrm{~h}$, returning after this to the first cage. Treatments lasted for $6(4$ trios) or 14 (4 trios) days. Only one female was present in each cage at a time and different males were used for different trios. Bedding was not renewed during the treatment period of any one trio.

Daily vaginal smears were taken in Exps B, C and D but not in A since it seemed possible the smearing procedure might cause ovulation. The results of Exps B, C and D have shown that this does not occur. Smears were stained with toluidine blue. At the end of each experiment the females were killed, their ovaries fixed in Bouin's fluid, serially sectioned at $7 \mu \mathrm{m}$ and stained with haematoxylin and eosin. 
Table 1. Remote influence of males upon ovulation and corpus luteum (CL) formation in bank voles

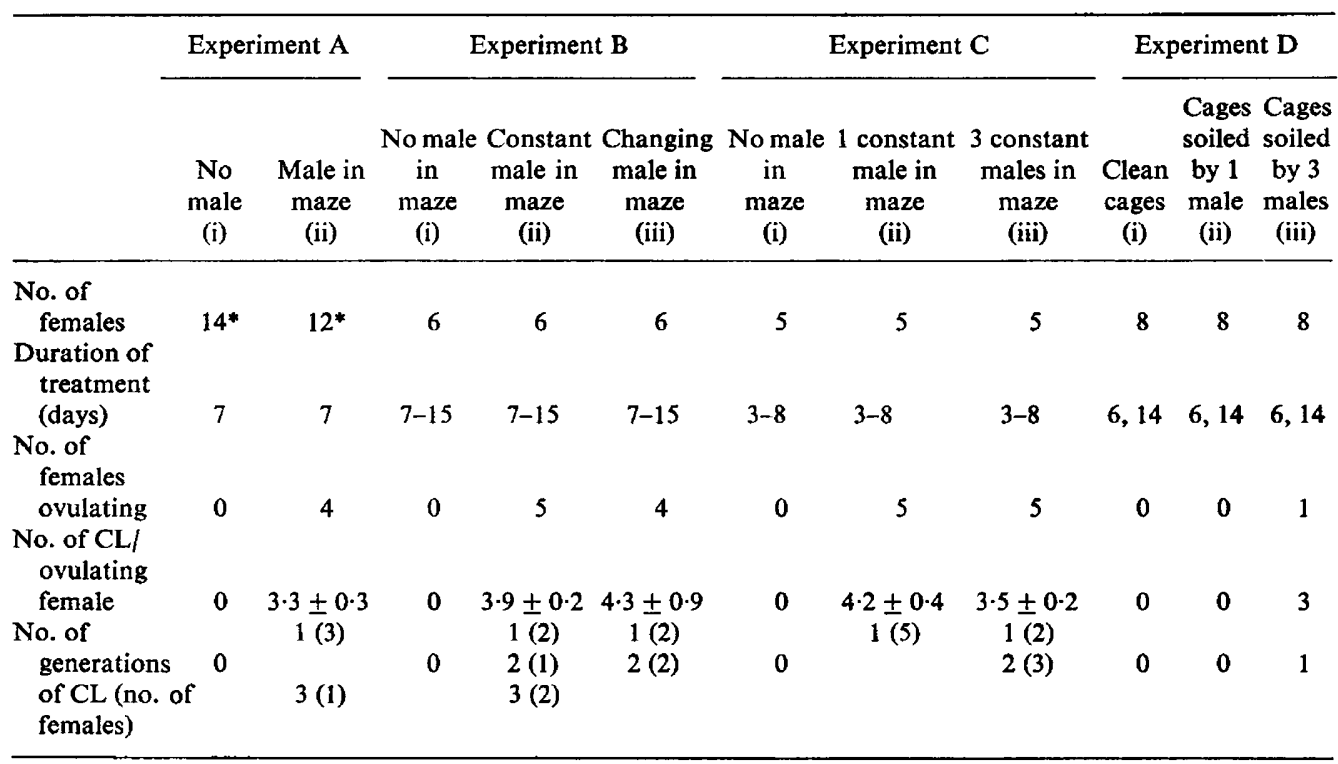

Values are mean \pm S.E.M.

* Deaths caused inequality of numbers.

The diameter of each corpus luteum (CL) was taken as the mean of two measurements at right angles through its largest section.

\section{Results and discussion}

As shown in Table 1, CL were found only when the treatment involved a male. The number of females ovulating differed, being 10/10 in Exp. C, 9/12 in Exp. B, 4/12 in Exp. A and 1/16 in Exp. D. The one female in Exp. $D$ that ovulated had been exposed for 14 days to the soiled bedding of 3 males. In a number of females two or three generations of CL could be recognized (Table 1). Those judged to be the most recent had healthy luteal cells and the former follicular antrum had not become filled by luteal cells. Middle-aged CL were identified by the absence of the antrum and by the onset of fatty degeneration and nuclear pyknosis in some of the luteal cells. The oldest generation was characterized by the degeneration of all but a few luteal cells, so that histologically they appeared lace-like. In Exps $B, C$ and $D$ the occurrence of $C L$ could be associated with a change from vaginal smears rich in cornified and nucleated epithelial cells to those consisting essentially of leucocytes, and occurring at 4-10-day intervals. Accepting the association between such leucocytic invasions and ovulations, the change in the smear can be related to a particular generation of CL whose approximate age can thus be estimated (see Text-fig. 1). Considering only those females which ovulated, the number of young, middle-aged and old $C L$ varied from 3.6 to 3.8 per female.

These experiments have shown that ovulation in bank voles can be induced by males through stimuli other than those provided by coitus. In this respect the bank vole resembles the vole (Microtus agrestis) (Milligan, 1974). The likelihood of ovulation does not appear to be affected by exposure of females to the same male for a number of days, or to a different male every 2 nd day, and there was no difference in the proportion of females ovulating when 1 or 3 males were used. Numbers of females are too small to allow any conclusion to be drawn about conditions which allow several generations of $\mathrm{CL}$ to be formed. The small number of females ovulating in Exp. A (33\%) could have been due to the fact that the single male was changed daily, or that 2 or 3 females were present simultaneously. Nevertheless, one female in Exp. A ovulated 3 times in 7 days. 


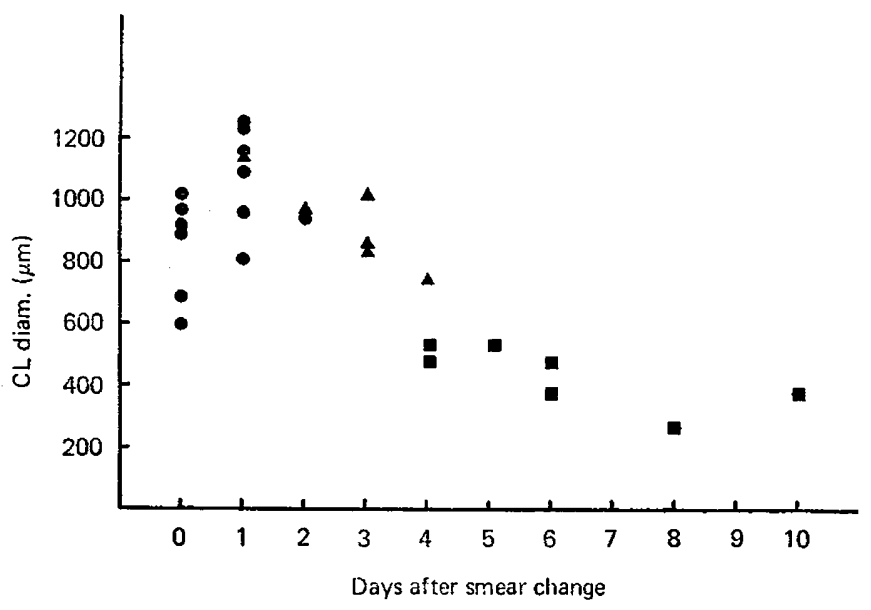

Text-fig. 1. Change in size of the CL found in bank voles, after ovulation induced remotely by males, with the leucocytic invasion of the vagina. Each point represents the mean diameter of all CL of any one generation

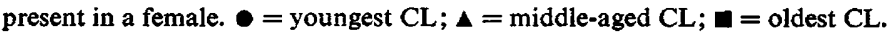

The nature of the effective stimuli provided by the male is uncertain. Although tactile, auditory, visual and olfactory stimuli could have passed from males to females in Exps A, B and C, olfactory stimuli, i.e. pheromones, may not have been very important because only 1 of 16 animals placed in soiled cages (Exp. D) ovulated. Milligan (1975) found that the most important non-coital stimulus causing ovulation in voles was tactile: pheromones seemed comparatively unimportant.

The mean ( \pm S.E.M.) number of CL/ovulating female in the present study $(3 \cdot 8 \pm 0 \cdot 2)$ is in close agreement with the number formed after mating $(4 \cdot 0 \pm 0 \cdot 3)$ (Clarke \& Clulow, 1973), indicating that the ovulatory stimulus was of the same order of magnitude as that occurring in natural mating. The CL which result from sterile mating in bank voles remain histologically healthy for about 9 days (J. R. Clarke, unpublished observations), whereas those found in the present experiments were short lived, several generations of CL being formed within 7-15 days. Although the males provided the ovulatory stimulus, luteotrophic activity sufficient to support CL for 9 days was lacking, as found by Milligan (1974) for voles exposed to similar treatments. The growth and decline in diameter of the short-lived CL in the bank vole follow a pattern essentially similar to that in the vole (Milligan, 1974), although bank vole CL reach a greater maximum size and regress slightly more slowly than do those of $M$. agrestis. Ovulations in the present study were associated with brief leucocytic invasions of the vagina occurring at intervals of 4-10 days, as has been found in the vole following non-coitally induced ovulations (Milligan, 1974). In one bank vole the ovulation cycle appeared to be 3-4 days long. Were an observer provided only with information about the state of the ovaries and changes in the vaginal smear, it could be erroneously concluded that the bank vole is a spontaneous ovulator with ovarian and vaginal cycles not unlike those of the mouse.

We are indebted to Professor J. H. Burnett for providing facilities for this work, and to Mrs Judith Baker for expert technical assistance.

\section{References}

Brambell, F.W.R. \& Rowlands, I.W. (1936) Reproduction of the Bank Vole (Evotomys glareolus Schreber). I. The oestrous cycle of the female. Phil. Trans. $R$. Soc. B 226, 71-97.

Breed, W.G. (1967) Ovulation in the genus Microtus. Nature, Lond. 214, 826.
Clarke, J.R. \& Clulow, F.V. (1973) The effect of successive matings upon bank vole (Clethrionomys glareolus) and vole (Microtus agrestis) ovaries. In The Development and Maturation of the Ovary and its Functions, pp. 160-170. Ed. H. Peters. Excerpta Medica Int. Congr. Ser. No. 267, Amsterdam. 
Clarke, J.R., Clulow, F.V. \& Greig, F. (1970) Ovulation in the bank vole, Clethrionomys glareolus. J. Reprod. Fert. 25, 531, Abstr.

Clulow, F.V. \& Mallory, F.F. (1970) Oestrus and induced ovulation in the meadow vole. Microtus pennsylvanicus. J. Reprod. Fert. 23, 341-343.

Cross, P.C. (1972) Observations on the induction of ovulation in Microtus montanus. J. Mammal.53, 210212.

Gray, G.D., Davis, H.N., ZeRYLnICK, M. \& Dews-
BURY, D.A. (1974) Oestrus and induced ovulation in montane voles. J. Reprod. Fert. 38, 193-196.

MilligaN, S.R. (1974) Social environment and ovulation in the vole, Microtus agrestis. J. Reprod. Fert, 41, 35-47.

Muluoan, S.R. (1975) Mating, ovulation and corpus luteum function in the vole, Microtus agrestis. J. Reprod. Fert. 42, 35-44.

RIChMOND, M. \& ConaWAY, C.H. (1969) Induced ovulation and oestrus in Microtus ochrogaster.J. Reprod. Fert., Suppl. 6, 357-376.

Received 29 November 1976 